\section{Case Reports in Ophthalmology}

Case Rep Ophthalmol 2016;7:202-207
(C) 2016 The Author(s)

Published by S. Karger AG, Basel

$1663-2699 / 16 / 0071-0202 \$ 39.50 / 0$

www.karger.com/cop

This article is licensed under the Creative Commons Attribution-NonCommercial 4.0 International License (CC BY-NC) (http://www.karger.com/Services/OpenAccessLicense). Usage and distribution for commercial purposes requires written permission.

\title{
Patch Grafting Using a Cryopreserved Descemet Stripping Automated Endothelial Keratoplasty Flap for Treating Corneal Perforation
}

\author{
Arisa Okada Ichiya Sano Yoshifumi Ikeda Etsuko Fujihara \\ Masaki Tanito \\ Division of Ophthalmology, Matsue Red Cross Hospital, Matsue, Japan
}

\section{Keywords}

Corneal perforation - Descemet stripping automated endothelial keratoplasty $\cdot$ Keratoplasty

Ocular emergency surgery

\begin{abstract}
A 73-year-old woman with a corneal perforation of undetermined etiology was treated with corneal patch grafting. A residual partial-thickness corneal button obtained during a previous Descemet stripping automated endothelial keratoplasty (DSAEK) surgery and stored at $-80^{\circ} \mathrm{C}$ in Optisol GS for 3 months was used as a patch graft. Five days postoperatively, the anterior chamber was reformed and the perforation was masked by the donor cornea. During the next several weeks, gradual displacement of the anterior edge of the donor cornea in the limbal direction occurred. Seven weeks postoperatively, further displacement of the donor cornea resulted in unmasking of the perforated area. At this time, the corneal defect was closed by stromal scar tissue and corneal epithelium. Five months postoperatively, best corrected visual acuity was 1.0 without marked astigmatism and intraocular pressure was $9 \mathrm{~mm}$ $\mathrm{Hg}$ in the left eye. From this case, we learned that cryopreserved DSAEK flaps stored longer than reported previously can be used as patch grafts to treat emergency conditions. Scar
\end{abstract}




\section{Case Reports in Ophthalmology}

tissue can fill a corneal stromal defect $1 \mathrm{~mm}$ in diameter during temporary patch grafting for less than 2 months.

\section{Introduction}

A corneal perforation requires emergency treatment to avoid vision-threatening complications including bacterial endophthalmitis and hypotony $[1,2]$. Several materials such as cryopreserved [3] and hyperdried [4] amniotic membrane, sclera [5], and cornea [6] have been used as patch grafts to close perforations. We report the case of a corneal perforation treated with cryopreserved partial-thickness corneal patch grafting. In this case, a scar tissue closed the corneal defect after gradual graft displacement.

\section{Case Presentation}

A 73-year-old woman, referred to a general ophthalmologist for a 1-week history of sudden tearing and decreased vision in her left eye (OS), presented to our hospital on the same day of the referral. Best corrected visual acuity and intraocular pressure in that eye were 0.15 and $2 \mathrm{~mm} \mathrm{Hg}$, respectively. Slit-lamp examination and ultrasound biomicroscopy showed a corneal perforation about $1 \mathrm{~mm}$ in diameter superotemporally, iris plugging, and flat anterior chamber (AC) OS (fig. 1a, b); fibrin formation and floating cells were in the AC, but endophthalmitis or an infectious corneal ulcer was not identified. The past history included uneventful small-incisional cataract surgery OS and vascular stent surgery for cardiac infarction several years previously. During farm work 2 months previously, the patient had reported a foreign-body sensation OS that subsided within a few days. The past history and blood/urinary laboratory examinations did not identify immunocompromised conditions, systemic infectious diseases, or steroid use. Cultures of scraped corneal tissue and AC fluid did not detect any microorganisms. The patient was diagnosed with a corneal perforation of undetermined etiology.

She was treated with corneal patch grafting on the same day. A residual partialthickness corneal button cut using a 350- $\mu \mathrm{m}$ microkeratome and an 8-mm-diameter donor punch during a previous Descemet stripping automated endothelial keratoplasty (DSAEK) surgery were used as a patch graft. Until use, the corneal button was stored at $-80^{\circ} \mathrm{C}$ in Optisol GS (Bausch \& Lomb, Rochester, N.Y., USA) for 3 months. After the limbal peritomy, iris plugging was released by injection of a viscoelastic into the AC. After débridement of the perforation edge and deepithelialization of the surrounding cornea, the corneal button, trimmed to two thirds of its size, was secured with 8 interrupted 10-0 nylon sutures on the host cornea and adjacent perilimbal sclera to cover the corneal defect. Prophylactic antibiotic treatment included 1 intravitreal injection of $2 \mathrm{mg}$ ceftazidime and $1 \mathrm{mg}$ vancomycin, oral cefdinir $300 \mathrm{mg}$ daily for 5 days, topical $0.3 \%$ ofloxacin ointment once daily for 5 days, and topical 1.5\% levofloxacin 6 times daily for 2 weeks and then 4 times daily for 1 month. Topical $0.1 \%$ betamethasone was started 3 times daily and tapered gradually but continued once daily until the last visit 5 months postoperatively.

Five days postoperatively, the AC was reformed and the perforation was masked by the donor cornea (fig. 1c). Anterior-segment optical coherence tomography (AS-OCT) images showed a corneal defect under the donor cornea (fig. 1d). During the next several weeks, gradual displacement of the anterior edge of the donor cornea in the limbal direction oc- 
Case Reports in
Ophthalmology

Case Rep Ophthalmol 2016;7:202-207 $10.1159 / 000445796$ www.karger.com/cop

Okada et al:: Patch Grafting Using a Cryopreserved Descemet Stripping Automated Endothelial Keratoplasty Flap for Treating Corneal Perforation

curred. Seven weeks postoperatively, further displacement of the donor cornea resulted in unmasking of the perforated area (fig. 1e). At this time, the corneal defect was closed by stromal scar tissue and corneal epithelium (fig. 1f); corneal topographic maps obtained by a rotating Scheimpflug camera (Pentacam; Oculus, Wetzlar, Germany) showed no marked astigmatism (fig. 2). Five months postoperatively, best corrected visual acuity was 1.0 without marked astigmatism, and intraocular pressure was $9 \mathrm{~mm} \mathrm{Hg} \mathrm{OS}$.

\section{Discussion}

At the initial visit to our hospital, we observed marked corneal surface vascularization extending from the limbus toward the corneal defect, suggesting that the pathology had started several weeks before the perforation. As reported by the patient, minor trauma 2 months previously could have been the etiology of the perforation. Based on the postsurgical observation, the anterior edge of the donor cornea seemed to be displaced by gradual melting of the donor tissue rather than shrinkage of the entire corneal button. Thus, sterile sclerocorneal melting is another possible underlying mechanism of corneal perforation in this case.

As reported previously, 'split corneal transplantation' that uses one donor cornea for two recipients by DSAEK and lamellar keratoplasty was scheduled simultaneously [7] or DSAEK was performed first followed by patch grafting a maximum of 4 weeks later using a remaining corneal flap stored at $4^{\circ} \mathrm{C}$ [8]. Thus, use of a DSAEK-derived corneal flap stored at $-80^{\circ} \mathrm{C}$ as a patch graft for corneal perforation is unique. When using full-thickness sclera [5] or cornea [6], to adjust the thickness these were required to dissect before patch grafting. Accordingly, its 'ready-to-use' thickness and size seemed to be the merit of the DSAEK flap as a patch graft. Previously, all 20 corneal flaps stored at $4^{\circ} \mathrm{C}$ were structurally intact at least 19 months after patch grafting [8]. Accordingly, we could not exclude the possibility that cryopreservation was related to the graft melting in the current case. It can be difficult for scar tissue to fill scleral stroma, probably because of its relatively poor vascularity and cellularity; however, it was reported that scleral patch grafting combined with a cyanoacrylate tissue adhesive for corneal perforations generally results in fibrous tissue formation [5]. We report that fibrous tissue formation can fill a corneal defect even after patch grafting, using a corneal button.

From this case, we learned that cryopreserved DSAEK flaps stored longer than reported previously can be used as patch grafts to treat emergency conditions. Scar tissue can fill a corneal stromal defect $1 \mathrm{~mm}$ in diameter during temporary patch grafting for less than 2 months.

\section{Statement of Ethics}

Written informed consent was obtained from the patient for publication of this case report and any accompanying images. 
Case Reports in
Ophthalmology

Case Rep Ophthalmol 2016;7:202-207 $10.1159 / 000445796$

www.karger.com/cop

Okada et al:: Patch Grafting Using a Cryopreserved Descemet Stripping Automated Endothelial Keratoplasty Flap for Treating Corneal Perforation

\section{Disclosure Statement}

The authors declare that there is no conflict of interest regarding the publication of this paper.

\section{References}

1 Yokogawa H, Kobayashi A, Yamazaki N, Masaki T, Sugiyama K: Surgical therapies for corneal perforations: 10 years of cases in a tertiary referral hospital. Clin Ophthalmol 2014;8:2165-2170.

2 Nivenius E, Montan P: Spontaneous corneal perforation associated with atopic keratoconjunctivitis: a case series and literature review. Acta Ophthalmol 2015;93:383-387.

-3 Savino G, Colucci D, Giannico MI, Salgarello T: Amniotic membrane transplantation associated with a corneal patch in a paediatric corneal perforation. Acta Ophthalmol 2010;88:e15-e16.

-4 Kitagawa K, Okabe M, Yanagisawa S, Zhang XY, Nikaido T, Hayashi A: Use of a hyperdried cross-linked amniotic membrane as initial therapy for corneal perforations. Jpn J Ophthalmol 2011;55:16-21.

-5 Sharma A, Mohan K, Sharma R, Nirankari VS: Scleral patch graft augmented cyanoacrylate tissue adhesive for treatment of moderate-sized noninfectious corneal perforations (3.5-4.5 mm). Cornea 2013;32:1326-1330.

-6 Rijneveld WJ, Wolff R, Volker-Dieben HJ, Pels E: Validation of tissue quality parameters for donor corneas, designated for emergency cases: corneal graft survival. Acta Ophthalmol 2011;89:734-740.

7 Sharma N, Agarwal P, Titiyal JS, Kumar C, Sinha R, Vajpayee RB: Optimal use of donor corneal tissue: one cornea for two recipients. Cornea 2011;30:1140-1144.

-8 Chu HS, Hsieh MC, Chen YM, Hou YC, Hu FR, Chen WL: Anterior corneal buttons from DSAEK donor tissue can be stored in Optisol GS for later use in tectonic lamellar patch grafting. Cornea 2014;33:555558. 


\section{Case Reports in Ophthalmology}

\begin{tabular}{l|l}
\hline Case Rep Ophthalmol 2016;7:202-207 \\
\hline $10.1159 / 000445796$ & $\begin{array}{l}\text { @ 2016 The Author(s). Published by S. Karger AG, Basel } \\
\text { www.karger.com/cop }\end{array}$ \\
\hline
\end{tabular}

Okada et al.: Patch Grafting Using a Cryopreserved Descemet Stripping Automated Endothelial Keratoplasty Flap for Treating Corneal Perforation
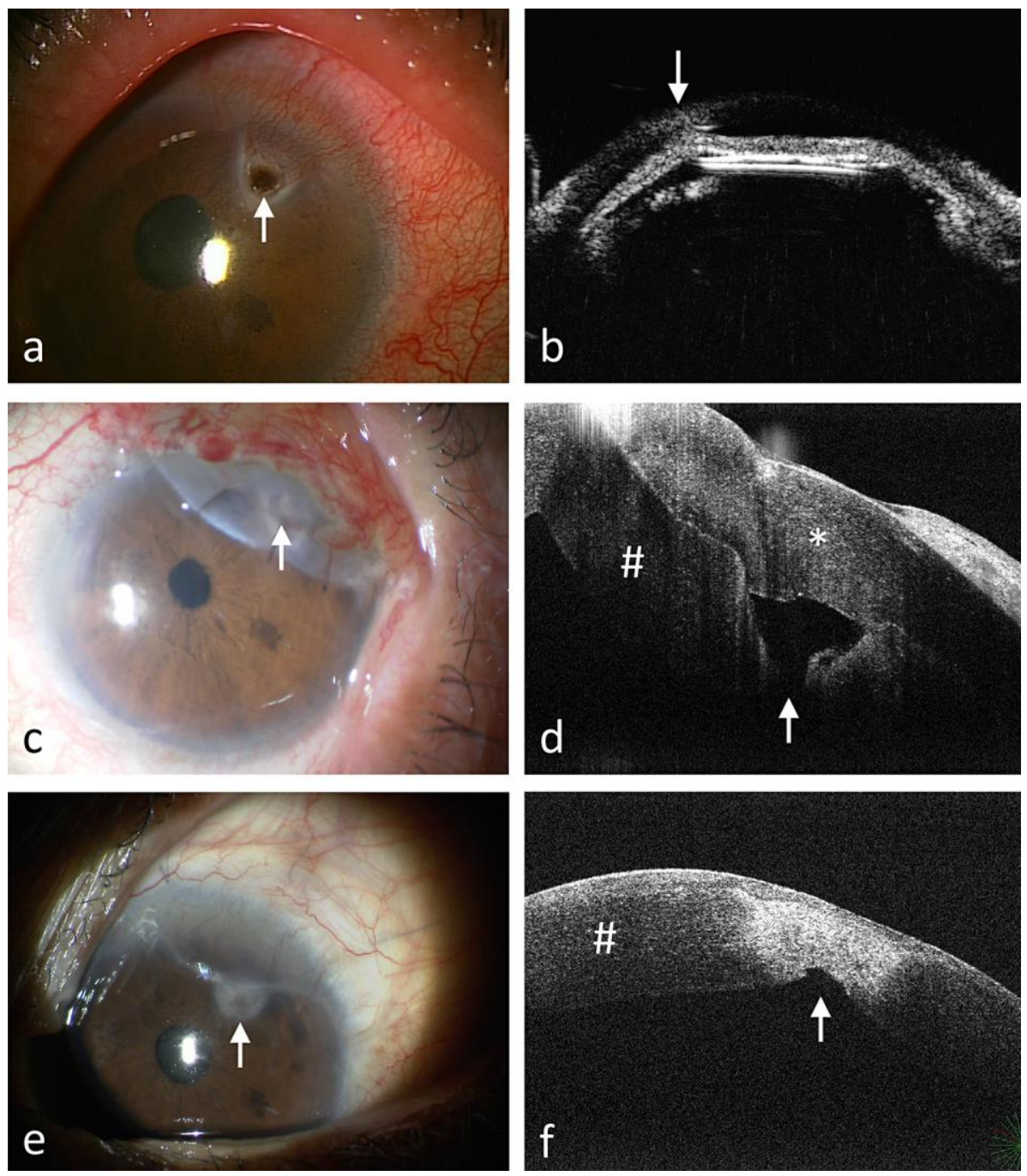

Fig. 1. Perioperative findings. At referral, a corneal perforation plugged by iris superotemporally (a, b; arrows) and a flat anterior chamber in the left eye are seen on slit-lamp examination (a) and ultrasound biomicroscopy (b). Slit-lamp examination (c) and AS-OCT (d) show that 5 days after corneal grafting, the donor corneal tissue ( $\mathbf{d}$; ${ }^{*}$ ) completely covers the corneal defect (c, d; arrows) on the host cornea (d, f; \#). Seven weeks postoperatively, slit-lamp examination (e) shows peripheral movement of the anterior edge of the patch graft and exposure of the previously perforated area (arrow). An AS-OCT (f) image shows that stromal scar tissue (arrow) covered by corneal epithelium has closed the corneal defect. 

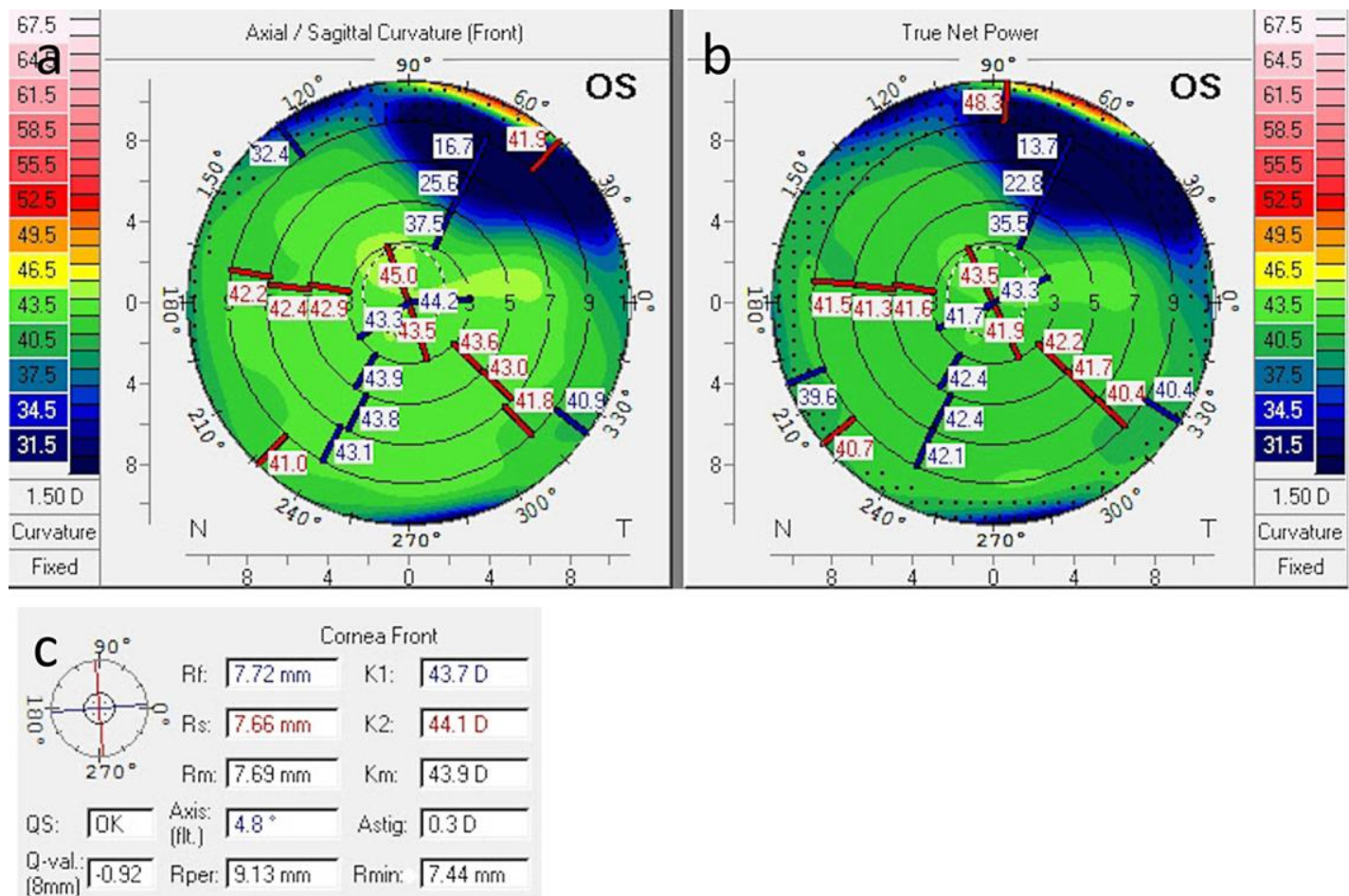

Q.val: $\sqrt{0.92}$ Riper: $\longdiv { 9 . 1 3 \mathrm { mm } }$ Rimin: $\longdiv { 7 . 4 4 \mathrm { mm } }$

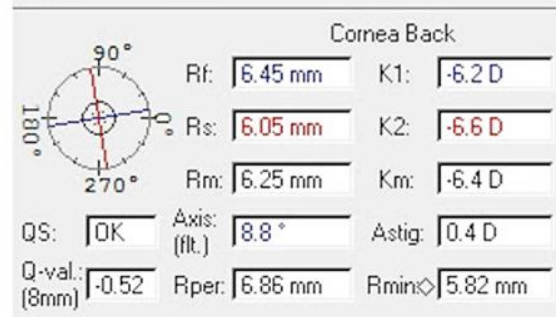

Fig. 2. Postoperative corneal topographic maps obtained with a Pentacam. Seven weeks postoperatively, no remarkable astigmatism is observed on the corneal front (a) and net (b) power maps. The astigmatism is calculated to be 0.3 and $0.4 \mathrm{D}$ on the corneal front and back, respectively (c). 